\section{GI symptoms as early signs of COVID-19 in hospitalised Italian patients}

In their recent publication in Gut, Lin et al report $11 \%$ of patients infected with SARS-CoV-2 (COVID-19) to present at admission with GI symptoms ${ }^{1}$; early observations reported that COVID-19 could present with GI symptoms in 3\% of patients. ${ }^{23}$ Diarrhoea, nausea, vomiting and/or abdominal pain or discomfort have been described at disease onset or even before respiratory symptoms. ${ }^{4-7}$

We investigated all consecutive individuals suspected to harbour COVID-19 and admitted at the General Hospital of Crema between 21 February and 13 March 2020 to assess prevalence and features of GI symptoms in COVID-19 patients and their correlation with medical history, disease course and outcome.

All suspected individuals admitted to the hospital underwent a standardised work-up. Based on clinical, laboratory and radiological findings, patients were discharged to quarantine or hospitalised. Demographic data, date of onset and type of symptoms at admission, including GI symptoms (as either nausea, or vomiting or diarrhoea or abdominal pain), and hospitalisation data were recorded. Primary outcomes were: need of continuous positive airway pressure (CPAP) or non-invasive ventilation (NIV), intensive care unit (ICU) admission and death.

Among 411 consecutive COVID-19 patients (with positive RT-PCR), 42 (10.2\%, 15 females and 27 males, mean age $68.2 \pm 14.2)$ reported GI symptoms including nausea $(18,4.3 \%)$, vomiting $(16$, $3.8 \%)$, diarrhoea $(15,3.6 \%)$ or abdominal pain $(5,1.2 \%)$. GI symptoms had a mean onset of $4.9 \pm 4.4$ days (range 1-20) before admission. Absence of cough was reported in 35/42 (83\%) patients with GI symptoms compared with 225/369 (61\%) patients without GI symptoms $(\mathrm{p}=0.004)$, with $15 \%$ vs $13 \%$ of them, respectively, having negative chest imaging. The frequency of fever was similar $(\mathrm{p}=0.7)$ in the two groups. In 5 of 411 patients (1.2\%), GI symptoms were neither associated with fever nor cough. GI symptoms did not show any significant 
correlation with syncope $(p=0.3)$, use of ACE inhibitors $(p=0.1)$, presence of comorbidities $(p=0.3)$ or use of multiple drugs $(\mathrm{p}=0.7)$. Of the 42 patients presenting with GI symptoms, $9(21.4 \%)$ required CPAP/ NIV, 1 (2.3\%) was admitted to ICU and 4 (9.5\%) died. Table 1 shows correlation of GI symptoms with outcomes as either CPAP/ NIV or ICU admission or death.

Our finding of $10 \%$ of patients confirms that the prevalence of GI symptoms at onset is not negligible. ${ }^{14}$

GI symptoms can herald COVID-19 as they presented on average 4.9 days before admission, with a very wide range with up to 20 days before admission. Our data confirm the importance of including GI symptoms among the spectrum of COVID-19 features, to allow early diagnosis and appropriate treatments even in patients without respiratory symptoms. This could be of particular importance considering the rapid human-tohuman transmission among close contacts, which could be related to GI viral infection and potential oral-faecal transmission, possibly persisting even after viral clearance from the respiratory tract. ${ }^{5}{ }^{8-10}$ In our cohort, GI symptoms did not correlate with fever, syncope, use of ACE inhibitors or multiple drugs, comorbidities. Conversely, we found a strong correlation with the absence of cough: we suggest that, as rate of lung involvement was similar in the two groups, patients with GI involvement might have a more silent lung involvement. Even if a possibly more benign disease course in patients with GI symptoms could be suggested by the trend of ICU admissions and deaths, which was lower compared with patients without GI symptoms at onset, the difference proved non-significant.

GI manifestations of COVID-19 are early, and possibly isolated, signs of the disease. Patient management and isolation policies should be accordingly tailored.

Elisabetta Buscarini ® , ${ }^{1}$ Guido Manfredi, ${ }^{1}$ Gianfranco Brambilla, ${ }^{1}$ Fernanda Menozzi, ${ }^{1}$

Table 1 Correlation of GI symptoms with CPAP/NIV, ICU admission or death

\begin{tabular}{llll}
\hline & Gl symptoms & Non-Gl symptoms & P value \\
\hline CPAP/NIV, $n(\%)$ & $9(21.4)$ & $103(27.9)$ & 0.37 \\
ICU, $\mathrm{n}(\%)$ & $1(2.4)$ & $27(7.3)$ & 0.23 \\
Death, $\mathrm{n}(\%)$ & $4(9.5)$ & $68(18.4)$ & 0.15 \\
\hline
\end{tabular}

CPAP, continuous positive airway pressure; ICU, intensive care unit; NIV, non-invasive CPAP, contin
ventilation.
Claudio Londoni, ${ }^{1}$ Saverio Alicante, ${ }^{1}$

Elena liritano, ${ }^{1}$ Samanta Romeo, ${ }^{1}$

Marianna Pedaci, ${ }^{1}$ Giampaolo Benelli, ${ }^{2}$

Ciro Canetta, ${ }^{3}$ Giuseppe La Piana, ${ }^{4}$ Guido Merli, ${ }^{5}$

Alessandro Scartabellati, ${ }^{6}$ Giovanni Viganò, ${ }^{7}$

Roberto Sfogliarini, ${ }^{8}$ Giovanni Melilli, ${ }^{8}$

Roberto Assandri, ${ }^{9}$ Daniele Cazzato, ${ }^{10}$

Davide Sebastiano Rossi, ${ }^{11}$ Susanna Usai, ${ }^{11}$

Irene Tramacere, ${ }^{12}$ Germano Pellegata, ${ }^{13}$

Giuseppe Lauria ${ }^{11,14}$

${ }^{1}$ Gastroenterology Department, ASST Maggiore Hospital, Crema, Italy

${ }^{2}$ Radiology Department, ASST Maggiore Hospital,

Crema, Italy

${ }^{3}$ Emergency Medicine Department, ASST Maggiore

Hospital, Crema, Italy

${ }^{4}$ Pneumology 1 Department, ASST Maggiore Hospital,

Crema, Italy

${ }^{5}$ Intensive Care Department, ASST Maggiore Hospital,

Crema, Italy

${ }^{6}$ Pneumology 2 Department, ASST Maggiore Hospital,

Crema, Italy

${ }^{7}$ Emergency Department, ASST Maggiore Hospital,

Crema, Italy

${ }^{8}$ Health Directorate, ASST Maggiore Hospital, Crema, Italy

${ }^{9}$ Clinical Investigation Laboratory, ASST Maggiore

Hospital, Crema, Italy

${ }^{10}$ Department of Diagnostics and Technology,

Fondazione IRCCS Istituto Neurologico "Carlo Besta",

Milan, Italy

${ }^{11}$ Department of Clinical Neurosciences, Fondazione IRCCS Istituto Neurologico "Carlo Besta", Milan, Italy

${ }^{12}$ Scientific Directorate, Fondazione IRCCS Istituto Neurologico "Carlo Besta", Milan, Italy

${ }^{13}$ General Directorate, ASST Maggiore Hospital, Crema, Italy

${ }^{14}$ Department of Biomedical and Clinical Sciences "Luigi Sacco", University of Milan, Milan, Italy

Correspondence to Dr Elisabetta Buscarini, Gastroenterology Department, Maggiore Hospital ASST Crema, Largo Dossena 2, Crema 26013, Italy; elisabetta.buscarini@asst-crema.it

Contributors Study concept and design: EB, GL. Study supervisors: RS, GP. Data collection : GMelilli, GBrambilla, FM, CL, RA, MP. Statistical analysis: IT. Analysis and interpretation of data: SA, El, SR, CC, AS. Drafting the manuscript: EB, GBenelli, GL, GV, GMerli. Critical revision of the manuscript for important intellectual content: DC, DSR, SU . Study submission: GManfredi. All the authors edited the manuscript and approved the final manuscript.

Funding The authors have not declared a specific grant for this research from any funding agency in the public, commercial or not-for-profit sectors.

Competing interests None declared.

Patient and public involvement Patients and/or the public were not involved in the design, or conduct, or reporting, or dissemination plans of this research.

Patient consent for publication Not required.

Provenance and peer review Not commissioned; internally peer reviewed.

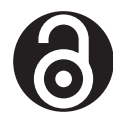

\section{OPEN ACCESS}

Open access This is an open access article distributed in accordance with the Creative Commons Attribution Non Commercial (CC BY-NC 4.0) license, which permits others to distribute, remix, adapt, build upon this work non-commercially, and license their derivative works on different terms, provided the original work is properly cited, appropriate credit is given, any changes made indicated, and the use is non-commercial. See: http://creativecommons.org/ licenses/by-nc/4.0/

(C) Author(s) (or their employer(s)) 2020. Re-use permitted under CC BY-NC. No commercial re-use. See rights and permissions. Published by BMJ.

Additional material is published online only. To view please visit the journal online (http://dx.doi.org/ 10.1136/gutjpl-2020-321434).

\section{Check for updates}

To cite Buscarini E, Manfredi G, Brambilla G, et al. Gut 2020;69:1547-1548.

Received 15 April 2020

Revised 6 May 2020

Accepted 7 May 2020

Published Online First 14 May 2020

Gut 2020;69:1547-1548. doi:10.1136/

gutjnl-2020-321434

ORCID iD

Elisabetta Buscarini http://orcid.org/0000-0003-0863-0624

\section{REFERENCES}

1 Lin L, Jiang X, Zhang Z, et al. Gastrointestinal symptoms of 95 cases with SARS-CoV-2 infection. Gut 2020;69:997-1001.

2 Wang D, Hu B, Hu C, et al. Clinical characteristics of 138 hospitalized patients with 2019 novel coronavirus-infected pneumonia in Wuhan, China. JAMA 2020;323:1061-9.

3 Chen N, Zhou M, Dong X, et al. Epidemiological and clinical characteristics of 99 cases of 2019 novel coronavirus pneumonia in Wuhan, China: a descriptive study. Lancet 2020;395:507-13.

4 Jin X, Lian J-S, Hu J-H, et al. Epidemiological, clinical and virological characteristics of 74 cases of coronavirusinfected disease 2019 (COVID-19) with gastrointestinal symptoms. Gut 2020;69:1002-9.

5 Gu J, Han B, Wang J. COVID-19: gastrointestinal manifestations and potential Fecal-Oral transmission. Gastroenterology 2020;158:1518-9.

6 Xiao F, Tang M, Zheng X, et al. Evidence for gastrointestinal infection of SARS-CoV-2. Gastroenterology 2020;158:1831-3

7 Gao QY, Chen YX, Fang JY. 2019 novel coronavirus infection and gastrointestinal tract. J Dig Dis 2020;21:125-6.

8 Zhang W, Du R-H, Li B, et al. Molecular and serological investigation of 2019-nCoV infected patients: implication of multiple shedding routes. Emerg Microbes Infect 2020;9:386-9.

9 Zhang $\mathrm{H}$, Kang Z, Gong $\mathrm{H}$, et al. Digestive system is a potential route of COVID-19: an analysis of single-cell coexpression pattern of key proteins in viral entry process. Gut 2020;69:1010-8.

$10 \mathrm{Ng} \mathrm{SC}$, Tilg H. COVID-19 and the gastrointestinal tract: more than meets the eye. Gut 2020;69:973-4 